\title{
Project D.A.R.E. Outcome Effectiveness Revisited
}

| Steven L. West, PhD, and Keri K. O'Neal, PhD

In the United States, Project D.A.R.E. (Drug Abuse Resistance Education) is one of the most widely used substance abuse prevention programs targeted at school-aged youths. In recent years, D.A.R.E. has been the country's largest single school-based prevention program in terms of federal expenditures, with an average of three quarters of a billion dollars spent on its provision annually. ${ }^{1}$ Although its effectiveness in preventing substance use has been called into question, its application in our nation's schools remains extensive. ${ }^{2-6}$

Given the recent increases in alcohol and other drug use among high school and college students, ${ }^{7}$ the continued use of D.A.R.E. and similar programs seems likely. In a meta-analysis examining the effectiveness of D.A.R.E., Ennett et al. ${ }^{3}$ noted negligible yet positive effect sizes (ranging from 0.00 to 0.11 ) when outcomes occurring immediately after program completion were considered. However, this analysis involved 2 major limitations. First, Ennett et al. included research from nonpeer-reviewed sources, including annual reports produced for agencies associated with the provision of D.A.R.E. services. While such an inclusion does not necessarily represent a serious methodological flaw, use of such sources has been called into question. ${ }^{8}$

Second, Ennett and colleagues included only studies in which postintervention assessment was conducted immediately at program termination. As noted by Lynam et al., ${ }^{6}$ the developmental trajectories of drug experimentation and use vary over time. Thus, if individuals are assessed during periods in which rates of experimentation and use are naturally high, any positive effects that could be found at times of lower experimentation will be deflated. Likewise, assessments made during periods in which experimentation and use are slight will exaggerate the overall effect of the intervention.

Ideally, problems such as those just described could be solved by the use of largescale longitudinal studies involving extensive follow-up over a period of years. There have been several longer term follow-ups,

Objectives. We provide an updated meta-analysis on the effectiveness of Project D.A.R.E. in preventing alcohol, tobacco, and illicit drug use among school-aged youths. Methods. We used meta-analytic techniques to create an overall effect size for D.A.R.E. outcome evaluations reported in scientific journals.

Results. The overall weighted effect size for the included D.A.R.E. studies was extremely small (correlation coefficient $=0.011$; Cohen $d=0.023 ; 95 \%$ confidence interval $=-0.04,0.08)$ and nonsignificant $(z=0.73, \mathrm{NS})$.

Conclusions. Our study supports previous findings indicating that D.A.R.E. is ineffective. (Am J Public Health. 2004;94:1027-1029)

but the cost of such efforts may limit the number of longitudinal studies that can be conducted. In the present analysis, we attempted to overcome this difficulty by including a wider range of follow-up reports, from immediate posttests to 10 -year postintervention assessments, in an updated metaanalysis of all currently available research articles reporting an outcome evaluation of Project D.A.R.E.

\section{METHODS}

We conducted computer searches of the ERIC, MEDLINE, and PsycINFO databases in late fall 2002 to obtain articles for the present study. In addition, we reviewed the reference lists of the acquired articles for other potential sources. We initially reviewed roughly 40 articles from these efforts; 11 studies appearing in the literature from 1991 to 2002 met our 3 inclusion criteria, which were as follows:

1. The research was reported in a peer-reviewed journal; reports from dissertations/theses, books, and unpublished manuscripts were not included. We selected this criterion in an attempt to ensure inclusion of only those studies with rigorous methodologies. As noted, a previous meta-analysis of Project D.A.R.E. included research from nonreviewed sources, a fact that critics have suggested may have added error to the reported findings. ${ }^{8}$ 2 . The research included a control or comparison group (i.e., the research must have involved an experimental or quasi-experimental design).
3. The research included both preintervention and postintervention assessments of at least 1 of 3 key variables: alcohol use, illicit drug use, and tobacco use. We chose to include only those effect sizes that concerned actual substance use behaviors, since the true test of a substance use prevention effort is its impact on actual rates of use.

Using these criteria, we refined the original list of studies to 11 studies (Table 1). We calculated effect sizes using the procedures outlined by Rosenthal. ${ }^{9}$ Meta-analysis results are commonly presented in the form of either a correlation coefficient $(r)$ or the difference in the means of the treatment and control conditions divided by the pooled standard deviation (Cohen's $d$ ) ${ }^{10}$ Since both are ratings of effect size, they can readily be converted to one another, and, if not provided in the original analyses, they can be calculated via $\mathrm{F}, t$, and $\chi^{2}$ statistics as well as means and standard deviations. ${ }^{9}$

We calculated both estimations for the individual included studies and for the overall analysis. As discussed by Amato and Keith, ${ }^{11}$ tests of significance used in meta-analyses require that effect sizes be independent; therefore, if 2 or more effect sizes were generated within the same outcome category, we used the mean effect size. We also used the procedure for weighting effect sizes suggested by Shadish and Haddock $^{12}$ to ensure that all effect sizes were in the form of a common metric. In addition, we calculated 95\% confidence intervals (CIs) for each study and for the overall analysis. 


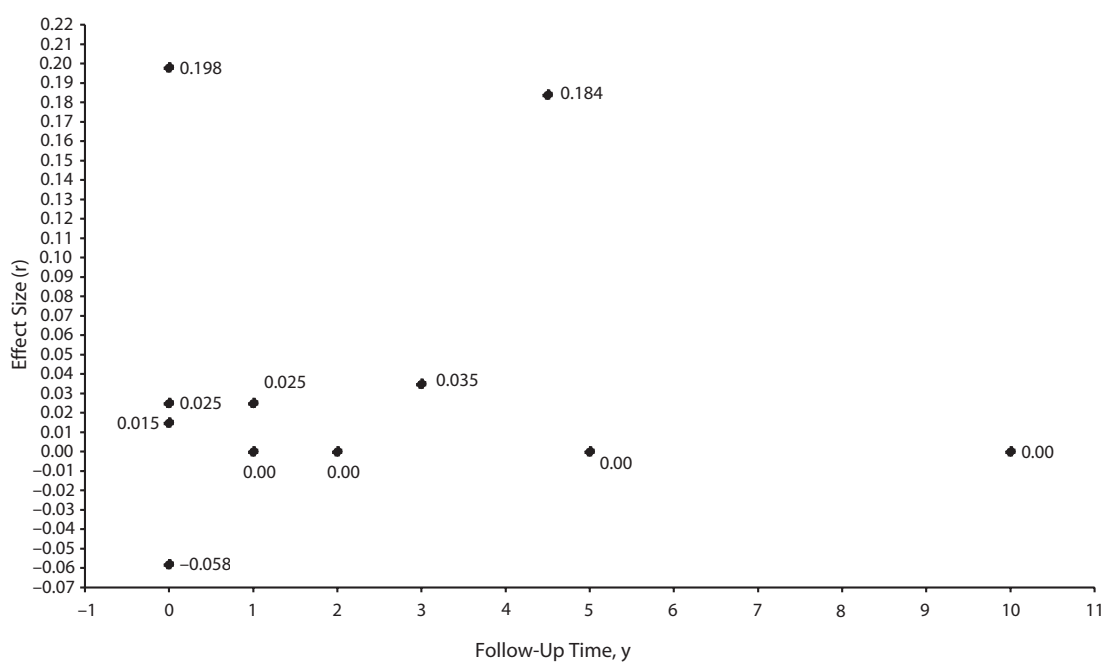

FIGURE 1-Plot of effect sizes, by follow-up time.

TABLE 1-Primary Articles Included in the Meta-Analysis

\begin{tabular}{|c|c|c|c|c|}
\hline Study (Year) & Sample & $r$ & $d$ & $\begin{array}{l}95 \% \text { Confidence } \\
\text { Interval }\end{array}$ \\
\hline Ringwalt et al. $(1991)^{18}$ & $\begin{array}{l}\text { 5th \& 6th graders ( } \mathrm{n}=1270 ; 52 \% \text { female/ } \\
\quad 48 \% \text { male; } 50 \% \text { African American } / 40 \% \text { Anglo/ } \\
10 \% \text { other), posttested immediately }\end{array}$ & 0.025 & 0.056 & $-0.06,0.16$ \\
\hline Becker et al. $(1992)^{19}$ & 5th graders $(n=2878)$, posttested immediately & -0.058 & -0.117 & $-0.19,-0.04$ \\
\hline Harmon $(1993)^{20}$ & 5th graders $(n=708)$, posttested immediately & 0.015 & 0.030 & $-0.12,0.18$ \\
\hline Ennett et al. $(1994)^{21}$ & $\begin{array}{l}\text { 7th \& } 8 \text { th graders ( } n=1334 ; 54 \% \text { Anglo/ } \\
22 \% \text { African American } / 9 \% \text { Hispanic/ } \\
15 \% \text { other), } 2 \text { years post-D.A.R.E. }\end{array}$ & 0.000 & $0.000^{\mathrm{a}}$ & $-0.11,0.11$ \\
\hline Rosenbaum et al. $(1994)^{22}$ & $\begin{array}{l}\text { 6th \& } 7 \text { th graders ( } \mathrm{n}=1584 ; \text {; } 49.7 \% \text { female/ } \\
50.3 \% \text { male; } 49.9 \% \text { Anglo/ } 24.7 \% \text { African } \\
\text { American/8.9\% Hispanic/16.5\% other) } \\
1 \text { year post-D.A.R.E. }\end{array}$ & 0.000 & $0.000^{\mathrm{a}}$ & $-0.10,0.10$ \\
\hline Wysong et al. $(1994)^{23}$ & 12th graders ( $n=619), 5$ years post-D.A.R.E. & 0.000 & $0.000^{\mathrm{a}}$ & $-0.16,0.16$ \\
\hline Dukes et al. $(1996)^{24}$ & 9th graders $(n=849), 3$ years post-D.A.R.E. & 0.035 & 0.072 & $-0.06,0.21$ \\
\hline Zagumny \& Thompson $(1997)^{25}$ & $\begin{array}{l}\text { 6th graders }(n=395 ; 48 \% \text { female } / 52 \% \text { male), } \\
4-5 \text { years post-D.A.R.E. }\end{array}$ & 0.184 & 0.376 & $0.07,0.68$ \\
\hline Lynam et al. $(1999)^{6}$ & $\begin{array}{l}\text { 6th graders ( } \mathrm{n}=1002 ; 57 \% \text { female } / 43 \% \text { male; } \\
75.1 \% \text { Anglo/ } 20.4 \% \text { African American/ } \\
0.5 \% \text { other), } 10 \text { years post-D.A.R.E. }\end{array}$ & 0.000 & $0.000^{\mathrm{a}}$ & $-0.15,0.15$ \\
\hline Thombs $(2000)^{26}$ & $\begin{array}{l}\text { 5th through } 10 \text { th graders }(n=630 ; 90.4 \% \text { Anglo, } \\
5.5 \% \text { African American, } 4.1 \% \text { other), } \\
\text { posttested at least } 1 \text { to } 6 \text { years post-D.A.R.E. }\end{array}$ & 0.025 & 0.038 & $-0.15,0.23$ \\
\hline Ahmed et al. $(2002)^{14}$ & $\begin{array}{l}\text { 5th and } 6 \text { th graders ( } n=236 ; 50 \% \text { female/ } \\
50 \% \text { male; } 69 \% \text { Anglo, } 24 \% \text { African American, } \\
7 \% \text { other), posttested immediately }\end{array}$ & 0.198 & 0.405 & $0.01,0.80$ \\
\hline
\end{tabular}

Note. $r=$ correlation coefficient; $d=$ difference in the means of the treatment and control conditions divided by the pooled standard deviation. Negative signs for $r$ and $d$ indicate greater effectiveness of control/comparison group. assumed effect size.

\section{RESULTS}

The average weighted effect size $(r)$ for all studies was $0.011(d=0.023 ; 95 \% \mathrm{CI}=-0.04$, 0.08 ), indicating marginally better outcomes for individuals participating in D.A.R.E. relative to participants in control conditions. The fact that the associated CI included a negative value indicates that the average effect size was not significantly greater than zero at $P<.05$. According to the guidelines developed by Cohen, ${ }^{13}$ both of the effect sizes obtained were below the level normally considered small. Four of the included studies noted no effect of D.A.R.E. relative to control conditions, and 1 study noted that D.A.R.E. was less effective than the control condition.

Furthermore, the 6 reports indicating that D.A.R.E. had more positive effects were, for the most part, small (Figure 1). The largest effect size was found in a report ${ }^{14}$ in which the only outcome examined was smoking. Finally, we conducted a test of cumulative significance to determine whether differences existed between D.A.R.E. participants and non-D.A.R.E. participants. This test produced nonsignificant results $(z=0.73$, NS).

\section{DISCUSSION}

Our results confirm the findings of a previous meta-analysis ${ }^{3}$ indicating that Project D.A.R.E. is ineffective. This is not surprising, given the substantial information developed over the past decade to that effect. Critics of the present analysis might argue that, despite the magnitude of our findings, the direction of the effect of D.A.R.E. was generally positive. While this is the case, it should be emphasized that the effects we found did not differ significantly from the variation one would expect by chance. According to Cohen's guidelines, ${ }^{13}$ the effect size we obtained would have needed to be 20 times larger to be considered even small. Given the tremendous expenditures in time and money involved with D.A.R.E., it would appear that continued efforts should focus on other techniques and programs that might produce more substantial effects.

Our findings also indicate that D.A.R.E. was minimally effective during the follow-up periods that would place its participants in the very age groups targeted. Indeed, no no- 
ticeable effects could be discerned in nearly half of the reports, including the study involving the longest follow-up period. This is an important consideration for those involved in program planning and development.

As noted earlier, progression in regard to experimentation and use varies over time. Use of alcohol and other drugs reaches a peak during adolescence or young adulthood and decreases steadily thereafter. ${ }^{7,15}$ Such a developmental path would be expected of all individuals, regardless of their exposure to a prevention effort. Ideally, individuals enrolled in a program such as D.A.R.E. would report limited or no use during their adolescent and young adult years. The fact that half of the included studies reported no beneficial effect of D.A.R.E. beyond what would be expected by chance casts serious doubt on its utility.

One shortcoming of our analysis should be noted. In many of the studies we included, individual students were the unit of analysis in calculating effects. As noted by Rosenbaum and Hanson, ${ }^{16}$ this practice tends to lead to overestimates of program effectiveness, since the true unit of analysis is the schools in which the students are "nested." Because our meta-analysis was limited to the types of data and related information available from the original articles, the potential for such inflation of program effectiveness exists. However, the overall effect sizes calculated here were small and nonsignificant, and thus it is unlikely that inclusion of studies making this error had a significant impact on the current findings.

An additional caveat is that all of the studies included in this analysis represent evaluations of what is commonly referred to as the "old D.A.R.E.": programs generally based on the original formulations of the D.A.R.E. model. In response to the many critiques of the program, the D.A.R.E. prevention model was substantially revamped in 2001, thanks in part to a $\$ 13.6$ million grant provided by the Robert Wood Johnson Foundation. ${ }^{17}$ The revisions to the model have since given rise to programs working under the "new D.A.R.E." paradigm. However, at the time of the writing of this article we were unable to find any major evaluation of the new D.A.R.E. model in the research literature, and the effectiveness of such efforts has yet to be determined.

\section{About the Authors}

Steven L. West is with the Department of Rehabilitation Counseling, Virginia Commonwealth University, Richmond. Keri K. O'Neal is with the Center for Developmental Science, University of North Carolina, Chapel Hill.

Requests for reprints should be sent to Steven $L$. West, PhD, Virginia Commonwealth University, Department of Rehabilitation Counseling, 1112 East Clay St, Box 980330, Richmond, VA 23298-0330 (e-mail: slwest2@vcu.edu).

This article was accepted January 5, 2003.

\section{Contributors}

S.L. West and K.K. O'Neal contributed equally to all aspects of study design, data analysis, and the writing of this article.

\section{Acknowledgments}

Portions of this research were presented at the Eighth Annual Meeting of the Society for Prevention Research, Montreal, Quebec, Canada, June 2000.

\section{Human Participant Protection}

No protocol approval was needed for this study.

\section{References}

1. McNeal RB, Hanson WB. An examination of strategies for gaining convergent validity in natural experiments: D.A.R.E. as an illustrative case study. Eval Rev. 1995; 19:141-158.

2. Donnermeyer J, Wurschmidt T. Educators' perceptions of the D.A.R.E. program. J Drug Educ. 1997;27: 259-276.

3. Ennett ST, Tobler NS, Ringwalt CL, Flewelling RL. How effective is Drug Abuse Resistance Education? A meta-analysis of Project DARE outcome evaluations. Am J Public Health. 1994;84:1394-1401.

4. Hanson WB. Pilot test results comparing the All Stars Program with seventh grade D.A.R.E.: program integrity and mediating variable analysis. Subst Use Misuse. 1996;31:1359-1377.

5. Hanson WB, McNeal RB. How D.A.R.E. works: an examination of program effects on mediating variables. Health Educ Behav. 1997;24:165-176.

6. Lynam DR, Milich R, Zimmerman R, et al. Project DARE: no effects at 10-year follow-up. J Consult Clin Psychol. 1999;67:590-593.

7. Johnston LD, O'Malley PM, Bachman JG. National Survey Results on Drug Use From the Monitoring the Future Study, 1975-1998. Volume I: Secondary School Students. Rockville, Md: National Institute on Drug Abuse; 1999. NIH publication 99-4660.

8. Gorman DM. The effectiveness of DARE and other drug use prevention programs. Am J Public Health. 1995;85:873.

9. Rosenthal R. Meta-Analytic Procedures for Social Research. 2nd ed. Thousand Oaks, Calif: Sage Publications; 1991.

10. DasEiden R, Reifman A. Effects of Brazelton demonstrations on later parenting: a meta-analysis. J Pediatr Psychol. 1996;21:857-868.

11. Amato PR, Keith B. Parental divorce and wellbeing of children: a meta-analysis. Psychol Bull. 1991; 110:26-46.
12. Shadish WR, Haddock CK. Combining estimates of effect size. In: Cooper H, Hedges LV, eds. The Handbook of Research Synthesis. New York, NY: Russell Sage Foundation; 1994:261-281.

13. Cohen J. Statistical Power Analysis for the Behavioral Sciences. 2nd ed. Hillsdale, NJ: Lawrence Erlbaum Associates; 1988.

14. Ahmed NU, Ahmed NS, Bennett CR, Hinds JE. Impact of a drug abuse resistance education (D.A.R.E.) program in preventing the initiation of cigarette smoking in fifth- and sixth-grade students. J Natl Med Assoc. 2002;94:249-256

15. Shedler J, Block J. Adolescent drug use and psychological health: a longitudinal inquiry. Am Psychol. 1990;45:612-630.

16. Rosenbaum DP, Hanson GS. Assessing the effects of a school-based drug education: a six-year multilevel analysis of Project D.A.R.E. J Res Crime Delinquency. 1998;35:381-412.

17. Improving and evaluating the DARE school-based substance abuse prevention curriculum. Available at: http://www.rwjf.org/programs/grantDetail.jsp?id=040371. Accessed January 8, 2003.

18. Ringwalt C, Ennett ST, Holt KD. An outcome evaluation of Project DARE (Drug Abuse Resistance Education). Health Educ Res. 1991;6:327-337.

19. Becker HK, Agopian MW, Yeh S. Impact evaluation of drug abuse resistance education (DARE). J Drug Educ. 1992;22:283-291.

20. Harmon MA. Reducing the risk of drug involvement among early adolescents: an evaluation of drug abuse resistance education (D.A.R.E.). Eval Rev. 1993; 17:221-239.

21. Ennett ST, Rosenbaum DP, Flewelling RL, Bieler GS, Ringwalt CL, Bailey SL. Long-term evaluation of drug abuse resistance education. Addict Behav. 1994;19: 113-125.

22. Rosenbaum DP, Flewelling RL, Bailey SL, Ringwalt CL, Wilkinson DL. Cops in the classroom: a longitudinal evaluation of drug abuse resistance education (D.A.R.E.). J Res Crime Delinquency. 1994;31:3-31.

23. Wysong E, Aniskiewicz R, Wright D. Truth and DARE: tracking drug education to graduation and as symbolic politics. Soc Probl. 1994;41:448-472.

24. Dukes RL, Ullman JB, Stein JA. Three-year followup of drug abuse resistance education (D.A.R.E.). Eval Rev. 1996;20:49-66.

25. Zagumny MJ, Thompson MK. Does D.A.R.E. work? An evaluation in rural Tennessee. J Alcohol Drug Educ. 1997;42:32-41.

26. Thombs DL. A retrospective study of DARE: substantive effects not detected in undergraduates. J Alcohol Drug Educ. 2000;46:27-40.

Subject codes 4, 53, 76, 77, 78 